\section{PHYSICAL METHODS OF GAS ANALYSIS}

$\mathrm{T}$ HE Physical Methods Group of the Society of Public Analysts and Other Analytical Chemists devoted a meeting held on May 2, at King's College, Newcastle-upon-Tyne, to a consideration of some applications of physical methods to the analysis of gases. Under the chairmanship of Mr. R. C. Chirnside, three short papers which dealt with widely differing aspects of the subject were read and discussed.

The first paper, by Dr. C. E. Ransley, on "Gas Analysis at Low Pressures", gave a brief review of the development of micro-gas analysis by this technique and described a new simplified procedure for the analysis of mixtures containing carbon monoxide, carbon dioxide, hydrogen, nitrogen and methane. $\mathrm{He}$ said that the feasibility of a relatively simple procedure for the analysis of very small volumes of gas at low pressures (namely, less than $0.1 \mathrm{~mm}$. of mercury) was first demonstrated so early as 1912 by Langmuir, in his classical work on gas reactions at solid surfaces. The number of papers published on applications of the method is not large, however, and nearly all have originated from the United States. Comparatively few workers in Great Britain appear to make use of this quite valuable research tool, possibly because the requisite facilities for the somewhat specialized high-vacuum work are not generally available. It is possible to analyse so little as 0.001 $\mathrm{ml}$. of gas by this method, and the type of apparatus used makes it particularly suitable for examination of the gases evolved from heated metals, glasses, ceramics and so on.

In developing a procedure for micro-analysis at low pressures it is possible to make use of some chemical reagents in a fairly orthodox manner. For example, in the method described by Prescott and Morrison ${ }^{1}$, reagents such as magnesium perchlorate and soda-lime were used in the form of small plugs containing only a fraction of a gram of powder, through which the gases were circulated by means of automatic Toepler or miniature diffusion pumps. There are objections, however, to the use of powdered reagents in vacuum systems, and it is preferable to make the maximum possible use of physical methods ; several advantages accrue, not the least of which is the fact that repeated measurements then become possible. In the procedure described, condensable gases are determined by means of the vapour pressuretemperature curve technique originated by Campbell ${ }^{2}$; or when water vapour and carbon dioxide are the only condensable gases present, these are readily measured by freezing out with freezing acetone or liquid air. Further, the specific diffusion of hydrogen through palladium provides a very useful method for the determination of this gas, and by arranging the apparatus so that the diffused hydrogen is collected for separate measurement, the accuracy can be considerably enhanced. Carbon monoxide and methane are determined by differential oxidation on neutral filaments, and the oxygen for this purpose is introduced into the system by diffusion through a heated silver tube. The carbon monoxide is oxidized at a platinum filament at $500^{\circ} \mathrm{C}$, and the methane at a platinum filament coated with alumina which is heated to $1,000^{\circ}-1,100^{\circ} \mathrm{C}$. The oxidation products are condensed into separate traps cooled with liquid air, and can be determined afterwards if necessary.
The discussion on this paper was mainly concerned with the separation of condensable gases by the Campbell method of microdistillation using the Pirani gauge. Dr. Ransley stated that if the condensation temperatures of the constituent gases are sufficiently widely separated, so that on warming the condensate the first gas attains its full partial pressure before the temperature rises to the condensation temperature of the second, and so on, a practical separation can readily be made.

The quantitative analysis of the natural and refinery gases of the type encountered in the petroleum industry is not an easy matter, since a sample may consist of anything from a simple binary mixture to a complex paraffin-olefin mixture containing up to a dozen or more constituents. Fortunately, the lighter hydrocarbons, containing one to five carbon atoms, have a comparatively wide boiling range (nearly $200^{\circ}$ C.), and the separation and analysis of these complex mixtures by fractional distillation at low temperatures was indicated as a feasible method of approach. Several types of apparatus for this purpose have been described in the literature, and some are available commercially; considerable contributions have been made in this field by Podbielniak ${ }^{3}$. Mr. J. H. D. Hooper, in the second paper given at the meeting ("The Analysis of Hydrocarbon Gases by Low Temperature Distillation"), gave an account of the development of the specialized apparatus used for this type of analysis, and indicated some of the practical difficulties which had to be overcome. The most recent advances have been in connexion with the design of the distillation column and condenser, and in the greater application of automatic devices to render the operator's task a little less arduous. Many forms of packing for the distillation column have been suggested; most of them are equivalent to 7-15 theoretical plates, but the new 'Heli-Grid' construction ${ }^{3}$ is reputed to be equivalent to about fifty equivalent plates. Mr. Hooper finds that by using this packing it is possible to separate such close-boiling components as iso-butane $\left(-11 \cdot 8^{\circ} \mathrm{C}\right.$.) and iso-butene $(-6 \cdot 8)$. The normal procedure in making an analysis is to separate the sample into fractions containing one, two, three, four and five carbon atoms per molecule. These fractions are then examined on subsidiary apparatus, or in special cases by different techniques such as absorption, combustion or spectroscopic methods.

So far as automatic devices are concerned, the most useful advances have been in the provision of automatic control of column pressure. It is possible now to obtain apparatus which plots the complete distillation curve of a sample, and such apparatus, although necessarily rather complicated and expensive, is capable of yielding more accurate results than can be obtained by manual control.

In reply to a question asked in the subsequent discussion, Mr. Hooper said that gas collection using pressure measurement is generally to be preferred to collection using volume measurement, because the manipulation is simpler. He also stated that sufficiently clear-cut fractionation of the $\mathrm{C}_{2}$ and $\mathrm{C}_{3}$ components can be made to enable the fractions to be examined by infra-red spectroscopy, without the strong ethylene band at $12 \mu$ obscuring the $\mathrm{C}_{s}$ spectrum.

The final paper, entitled "A New Apparatus for Gas Analysis by the Soap Film Method", was given by Mr. W. J. Gooderham. He also demonstrated the first commercial unit produced in accordance with 
his principles, an impressive piece of apparatus which aroused considerable interest. His procedure is perhaps only admissible as a 'physical method' by virtue of the fact that the extensive chemistry involved in the analysis is very unobtrusively and automatically performed. In introducing his paper, Mr. Gooderham said that given a series of accurate gas meters which do not appreciably absorb gas or cause loss of pressure, the simplest form of gas analysis can be obtained by passing gas through a meter, a reagent which removes one constituent completely, another meter, another reagent and so on. The soap-film meter, which he has described in earlier papers ${ }^{4}$, is ideal for this purpose. The apparatus demonstrated was arranged for the analysis of coal gas; this operation only took a minute or so to carry out, and the percentage analysis of a sample could be read directly from the meters. This was done by allowing the initial intake meter to move up 100 divisions, and then noting the change in each of the other meters, which represented the gas volume after successive constituents had been removed. Conventional reagents were used for absorption; but it was necessary to design the absorption pipettes so that only a very small back-pressure was developed.

Since the method is a dynamic one, a certain minimum passage of gas through the apparatus is necessary before reproducible final analyses were obtained. Several speakers in the discussion referred to this point, and $\mathrm{Mr}$. Gooderham said that $1-1 \frac{1}{2}$ litres of gas is usually sufficient to complete a full analysis with several repeats, and the sweeping-out operation, which normally took half an hour or so, could be speeded up if required. He also stated, in reply to other questions, that the accuracy of the apparatus is $0 \cdot 2$ per cent on each constituent, but that it might be possible to design for a greater sensitivity than this. Apparatus for the determination of carbon dioxide, oxygen and carbon monoxide in waste gases has also been made and used. It is preferable to use a special acidic soap solution for the meters.

The meeting was a pleasant and profitable one. It is expected that the papers which were read will shortly be reproduced in full in The Analyst.

1 Prescott, C. H., and Morrison, J., Indust. Eng. Chem. (Anal. Ed.), 11, 230 (1939)

2 Campbell, N. R., Proc. Phys. Soc., 33, 287 (1921).

Podbielniak, W. J., Indust. Eng. Chem. (Anal. Ed.), 3, 177 (1931);

5, (1933) 119; 5, 172 (1933); 13, 639 (1941).

- Gooderham, W. J., J. Soc. Chem. Ind., 59, 1 (1940); 63, 351 (1944).

\section{CONGRESS OF THE \\ INTERNATIONAL ASSOCIATION FOR THE PROTECTION OF INDUSTRIAL PROPERTY}

$\mathrm{T}$

HE Congress of the International Association

for the Protection of Industrial Property (sometimes affectionately termed 'Pip') was held recently at The Hague at the invitation of the Netherlands Group of the Association. This Congress had been originally fixed for 1940 .

The Association is an informal body of industrialists, patent agents, barristers and solicitors who are directly interested in questions relating to inventions, designs, trade marks and copyright. The expression 'industrial property' is a convenient portmanteau phrase for describing commercial rights connected with international trade and industry. It was largely as a result of the endeavours of the Association that the International Convention of 1883 was signed by the representatives of forty countries. The Convention agreement is not binding upon the domestic legislation of the countries adhering to it. It is, in effect, a code of conduct to facilitate international trade, and one of its main objects is to prevent all kinds of unfair trading.

The Association maintains a constant watch over international relationships in these matters, and the Congress at The Hague was an outstanding example of its activities. There were about four hundred delegates from most of the countries of the world except the U.S.S.R., Germany and Japan. The British group comprised about fifty delegates including seven counsel, and the British point of view was expressed with commendable clarity.

On the opening day of the Congress the president of the British Group, Mr. Lionel F. Heald, K.C., submitted a proposal that any question relating to the interpretation of the language of the International Convention should be referred to the International Court of Justice at The Hague. After a lively and well-informed discussion in which the great majority of the countries represented took part, the president of the Association (Senator Marcel Plaisant of France) was able to announce that the proposition had been carried unanimously.

Another interesting matter which caused much discussion concerned the translation of trade marks from one language to another. When goods have been sold under a 'trade name' which is a word in the vernacular of one of the countries, it may happen that a trader in another country may attempt to market similar goods in that foreign country under the name which is a translation of this word. The British delegation urged that if goods were registered abroad under a word in the language of origin of the goods, then that registration should cover the translation of the word in the vernacular of the foreign country. Although this view was not accepted by the Conference as a whole, it was unanimously agreed that a word and its translations in other countries could be registered at one and the same time, and that this step would be helpful in avoiding unfair trading.

By the Convention of 1883 , an International Office of the Association was established at Berne and was placed under the authority of the Swiss Government. This Office centralizes information of every kind relating to the protection of industrial property, and pablishes it. To facilitate this important work, it was resolved that countries adhering to the Convention should communicate to the Berne office all acts and statutory rules and orders relating to industrial property arising in the course of their domestic legislation. If any country failed to carry out the reciprocal commitments contained in the Convention, it was felt that the International Office at Berne should have powers to bring this fact to the attention of the Government of the country in question. The International Association should be given powers to formulate officially any opinion which it might be asked to give by the Government of any adherent country concerning its interpretation of the Convention.

One resolution concerned a modification of the procedure for priority rights in other countries in respect of an application for a patent or for the registration of a utility model, industrial design or trade mark in one of the Convention countries. 